\title{
OTOMATISASI SISTEM ANTREAN MENGGUNAKAN FAST METHODOLOGY: STUDI KASUS STUDENT ADVISORY UNIVERSITAS BINA NUSANTARA
}

\author{
Eileen Heriyanni; Josef Bernadi Gautama; Reina \\ School of Computer Science, BINUS University \\ Jln. K.H. Syahdan No. 9, Palmerah Jakarta Barat 11480 \\ eheriyanni@binus.edu; jbernadi@binus.edu; reina@binus.edu
}

\begin{abstract}
If there is a stack in a service center, then the customers need to form a queue. There are increasing number of consultations in a specific time at Student Advisory Center (SAC) Bina Nusantara University. The increased needs for consultation lead to high waiting time that must be passed by the students who need the service. Therefore an information system queue is required to replace the current manual queue process. This study aims to create an automation using six stages FAST Methodology which includes Scope Definition, Problem Analysis, Requirement Analysis, Logical Design, Decision Analysis, Physical Design and Integration. The results of this research is the design of the application queue screen can be applied to SAC Bina Nusantara University.
\end{abstract}

Keywords: FAST methodology, queue system automation, service center

\begin{abstract}
ABSTRAK
Jika terjadi penumpukan di sebuah pusat layanan, maka customer yang ada harus membentuk satu antrean. Pada Student Advisory Center (SAC) Universitas Bina Nusantara terjadi peningkatan jumlah konsultasi pada waktu waktu tertentu. Peningkatan kebutuhan akan konsultasi ini menimbulkan tingginya waktu tunggu bagi mahasiswa yang membutuhkan layanan. Untuk itu dibutuhkan sistem informasi antrean untuk mengganti proses antrean manual yang saat ini berjalan. Penelitian ini bertujuan untuk membuat otomatisasi sistem antrean dengan menggunakan 6 tahapan FAST Methodology yang mencakup Scope Definition, Problem Analysis, Requirement Analysis, Logical Design, Decision Analysis, Physical Design and Integration. Hasil dari penelitian ini adalah rancangan layar aplikasi antrean yang dapat diterapkan pada SAC Universitas Bina Nusantara.
\end{abstract}

Kata kunci: metodologi FAST, otomatisasi sistem antrean, pusat layanan 


\section{PENDAHULUAN}

Setiap Universitas memberikan bimbingan dan arahan mengenai pendidikan yang sedang ditempuh kepada seluruh mahasiswanya lewat dosen pembimbing akademik. Hal ini juga berlaku di Universitas Bina Nusantara. Sebagai tambahannya, Universitas bina Nusantara juga memfasilitasi setiap mahasiswanya lewat layanan akademis maupun nonakademis yang bernaung dalam sebuah unit yakni Student Advisory Center (SAC). SAC memiliki tiga layanan, yaitu mentoring, personal development, dan konseling. Program mentoring bertujuan untuk membantu mahasiswa dalam meningkatkan prestasi belajar. Dengan mengikuti program ini, para mahasiswa diharapkan mampu memahami dan menguasai materi-materi kuliah yang diambil pada semester berjalan melalui proses bimbingan belajar yang dilakukan antara Mentor dan Mentee. SAC mengadakan program-program pelatihan yang bertujuan untuk membentuk mahasiswa yang 'Smart and Good' lewat program personal development. Sementara program konseling bertujuan untuk membantu mahasiswa dalam meningkatkan kualitas hidup mahasiswa baik dalam bidang akademik maupun personal.

Menurut West, Watts, Trepal, Wester, dan Lewis (2001), counseling is an intentional effort (e.g., helping the client identify preferred directions in life). Berdasarkan data dari SAC, jumlah mahasiswa yang melakukan konseling per semesternya berjumlah lebih dari 3900 antrean yang dilayani. Data layanan konseling pada 2014 ditunjukkan dari Tabel 1.

Tabel 1 Jumlah Antrean Mahasiswa

\begin{tabular}{cc}
\hline Bulan & Jumlah Antrean \\
\hline Januari 2014 & 1100 \\
Februari 2014 & 800 \\
Maret 2014 & 400 \\
April 2014 & 300 \\
\hline
\end{tabular}

Antrean ini dilayani oleh Konselor pada subbiro konseling di SAC. Tercatat, pada Januari 2014 subbiro konseling memiliki 6 Konselor yang sudah menempuh pendidikan Psikologi. Berdasarkan data history terdapat lonjakan frekuensi konseling yang cukup signifikan pada waktu tertentu. Untuk melayani 1 orang mahasiswa, para Konselor membutuhkan waktu rata-rata 10-20 menit. Ditambah lagi, sistem antrean yang digunakan saat ini masih manual, yaitu menggunakan buku tamu di depan pintu SAC dan para Konselor harus secara berkala mengecek apakah ada antrean atau tidak pada buku tamu tersebut.

Berdasarkan permasalahan tersebut, penelitian ini bertujuan untuk mengatasi lonjakan jumlah antrean pada subbiro konseling dengan mengotomasi sistem antrean yang ada agar pelayanan konsultasi mahasiswa dapat berjalan baik. Menurut Martha, Sukarsa, dan Kencana (2012), antrean merupakan proses pembentukan suatu populasi yang terdiri dari para pelanggan yang sedang menunggu untuk mendapatkan pelayanan. Sedangkan menurut Gross dan Harris (1985), sistem antrean adalah kedatangan pelanggan untuk mendapatkan pelayanan, menunggu untuk dilayani jika fasilitas pelayan masih sibuk. Hal ini sejalan dengan keinginan untuk memberikan pelayanan yang optimal kepada para customer, sehingga dibutuhkan sistem informasi dengan metode antrean yang tepat (Suryadhi \& Manurung, 2009). 


\section{METODE}

Penelitian ini menggunakan FAST Methodology sebagai metode penelitiannya. FAST Methodology dinilai sesuai dalam mendesain aplikasi yang belum pernah dibuat. Dengan menggunakan metode ini, aplikasi dapat dibuat sesuai dengan kebutuhan organisasi. Langkah-langkah pada metode ini mencakup: 1. Scope Definition, 2. Problem Analysis, 3. Requirement Analysis, 4. Logical Design, 5. Decision Analysis, 6. Physical Design and Integration. Pada tahap Scope Definition, ruang lingkup penelitian ditentukan agar tidak terjadi pelebaran masalah saat melakukan analisis. Selanjutnya dilakukan tahapan problem analysis. Pada tahap ini masalah yang terjadi akan dipaparkan, sehingga dapat dicari sumber permasalahan. Pada tahap ini juga dapat ditentukan solusi yang ingin diberikan atas dasar permasalahan yang dihadapi. Tahap selanjutnya adalah menentukan kebutuhan apa saja yang dibutuhkan oleh user agar dapat mengatasi masalah yang ada pada poin sebelumnya. Descision Analysis dilakukan untuk memutuskan bentuk sistem yang digunakan untuk penyelesaian masalah yang terjadi. Tahapan terkahir yang dilakukan adalah physical design, yaitu merancang tampilan layar agar mempermudah pembuatan program aplikasi nantinya.

\section{HASIL DAN PEMBAHASAN}

\section{Ruang Lingkup}

Sistem yang akan dibangun adalah sistem antrean untuk konseling pada SAC Universitas Bina Nusantara. Tujuan dari pengembangan sistem antrean ini adalah mengoptimalkan pelayanan konseling pada client (mahasiswa dan orang tua) agar tidak terlalu lama menunggu. Observasi dilakukan untuk mengetahui kebutuhan dasar perancangan sistem.

\section{Analisis Masalah}

Permasalahan yang mungkin timbul dari pengembangan Sistem Antrean Konseling pada SAC Universitas Bina Nusantara, dapat dikelompokan dalam Tabel 2.

Tabel 2 Analisis Masalah

\begin{tabular}{|c|c|c|c|}
\hline \multicolumn{2}{|c|}{ ANALISIS PENYEBAB DAN AKIBAT } & \multicolumn{2}{|c|}{ TUJUAN PERBAIKAN SISTEM } \\
\hline Masalah/Peluang & Penyebab dan Akibat & Tujuan & Solusi \\
\hline $\begin{array}{l}\text { Belum ada proses } \\
\text { otomatisasi sistem } \\
\text { antrean pada } \\
\text { konseling SAC } \\
\text { Universitas Bina } \\
\text { Nusantara }\end{array}$ & $\begin{array}{ll}\text { - } & \text { Antrean masih dilakukan } \\
\text { secara manual dengan } \\
\text { menuliskan NIM, nama, dan } \\
\text { jurusan mahasiswa } \\
\text { Sistem antrean yang sedang } \\
\text { berjalan masih manual dan para } \\
\text { Konselor harus terus menerus } \\
\text { bolak-balik dari meja kerja } \\
\text { untuk mengeceknya di buku } \\
\text { tamu yang letaknya ada di } \\
\text { depan pintu masuk. }\end{array}$ & $\begin{array}{l}\text { Mengotomatisasi sistem } \\
\text { antrean }\end{array}$ & $\begin{array}{l}\text { Sistem mencatat } \\
\text { setiap kedatangan } \\
\text { client }\end{array}$ \\
\hline 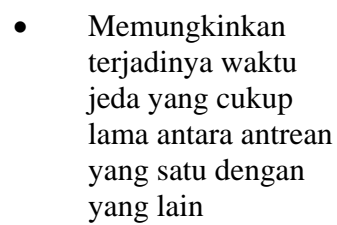 & $\begin{array}{l}\text { - Jika dalam suatu waktu } \\
\text { Konselor tidak ada client dan } \\
\text { mendadak menjelang akhir ada } \\
\text { client yang datang, sementara } \\
\text { Konselor sudah mengecek } \\
\text { buku tamu kosong maka dapat }\end{array}$ & $\begin{array}{l}\text { Mengoptimasi antrean } \\
\text { client }\end{array}$ & $\begin{array}{l}\text { Sistem memiliki } \\
\text { fasilitas notifikasi } \\
\text { kepada semua } \\
\text { Konselor untuk setiap } \\
\text { client yang datang, }\end{array}$ \\
\hline
\end{tabular}




\begin{tabular}{|c|c|c|c|}
\hline \multicolumn{2}{|c|}{ ANALISIS PENYEBAB DAN AKIBAT } & \multicolumn{2}{|c|}{ TUJUAN PERBAIKAN SISTEM } \\
\hline Masalah/Peluang & Penyebab dan Akibat & Tujuan & Solusi \\
\hline $\begin{array}{l}\text { - } \quad \text { Pembuatan laporan } \\
\text { proses konseling } \\
\text { dengan client butuh } \\
\text { waktu yang lama } \\
\text { dan tidak efisien }\end{array}$ & $\begin{array}{l}\text { terjadi jeda yang cukup lama } \\
\text { antara client sebelumnya } \\
\text { dengan client yang baru saja } \\
\text { datang karena Konselor tidak } \\
\text { sering mengecek buku tamu. } \\
\text { Tidak efisien jika terus } \\
\text { menerus harus mengecek } \\
\text { secara manual bahwa ada client } \\
\text { yang sedang menunggu. } \\
\text { Client tidak dapat terus } \\
\text { menunggu karena mereka juga } \\
\text { memiliki aktivitas yang lain di } \\
\text { luar sana. } \\
\text { Pelaporan manual dengan } \\
\text { menghitung setiap harinya ada } \\
\text { berapa client yang datang, } \\
\text { clustering frekuensi } \\
\text { kedatangan client yang sama } \\
\text { dalam sebulan, client dari } \\
\text { jurusan tertentu dan dari } \\
\text { angkatan tertentu, dan lain } \\
\text { sebagainya }\end{array}$ & $\begin{array}{l}\text { Penyajian laporan konseling } \\
\text { cepat dan akurat }\end{array}$ & $\begin{array}{l}\text { Sistem memiliki } \\
\text { fasilitas laporan } \\
\text { konseling di sisi back } \\
\text { end }\end{array}$ \\
\hline
\end{tabular}

\section{Analisis Kebutuhan}

Berdasarkan hasil observasi di SAC Universitas Bina Nusantara, diketahui bahwa dalam proses antrean sepenuhnya masih dilakukan secara manual. Belum ada proses otomatisasi yang terjadi. Proses yang biasanya terjadi adalah client datang, mengisi buku tamu, kemudian menunggu untuk dipanggil. Setelah dipanggil oleh Konselor, sesi konseling dimulai. Permasalahan yang biasa terjadi adalah client datang dan menunggu untuk dilayani. Namun karena tidak ada pemanggilan terhadap client yang bersangkutan, client mengganti konseling ke hari lain atau bahkan tidak datang lagi karena terlalu lama menunggu. Hal ini disebabkan Konselor sudah mengecek buku tamu namun kosong, setelah itu ada client yang baru datang dan Konselor tidak tahu ada client yang datang kemudian. Ditambah lagi, jarak antara buku tamu dengan meja kerja masing-masing Konselor cukup jauh dan frekuensi pengecekan buku tamu secara manual untuk benar-benar memastikan ada tidaknya client yang sedang menunggu sangat tidak efisien.

Berdasarkan analisis masalah yang telah dilakukan, maka diajukan sebuah otomatisasi sistem antrean konseling yang mampu mengoptimasi antrean dan mengefisiensikan kinerja para Konselor dalam melakukan sesi konseling. Interaksi terhadap sistem antrean dilakukan oleh admin, Konselor, dan client dengan role yang berbeda-beda. Sistem ini akan berjalan pada 2 sisi yakni sisi client dan sisi back end. Fasilitas login akan disediakan pada sisi back end untuk dapat berinteraksi dengan sistem. Role Admin dapat me-reset sistem antrean setiap harinya dan dapat dengan mudah men-generate laporan per bulan terkait berapa banyak proses konseling yang terjadi dengan client sesuai dengan kebutuhannya (misalnya per jurusan, per angkatan, dsb). Setiap client, baik mahasiswa dan orang tua, yang datang dan ingin mengantre untuk melakukan sesi konseling dapat mengetikkan NIM mahasiswa yang bersangkutan, kemudian sistem akan memunculkan nomor antrean bagi client. Sementara itu, NIM, nama, jurusan, dan waktu kunjungan akan terbaca dan terekam pada sistem sisi back end.

Setelah mendapatkan nomor antrean, client dapat menunggu sampai dipanggil. Setiap Konselor akan diberikan sebuah fasilitas notifikasi yang akan memberitahukan setiap kedatangan client dan dapat dengan segera memanggil client yang sedang menunggu. Sesaat sebelum client dipanggil, Konselor harus mencentang terlebih dahulu client mana dari daftar antrean yang ingin 
dilayani agar tidak terjadi kesalahan, seperti: client yang sama dilayani oleh 2 Konselor, client yang telah dilayani masih berada dalam daftar antrean dan dipanggil kembali oleh Konselor lain, dll.

\section{Logical Design}

Berdasarkan analisis kebutuhan terdapat empat proses utama yang akan difasilitasi oleh sistem, yaitu 1. pendaftaran untuk mendapatkan nomor antrean, 2. notifikasi kedatangan client, 3. mengeluarkan client yang telah dilayani dari nomor antrean, dan 4. pendataan sesi konseling yang terjadi. Berikut adalah use case sistem antrean konseling yang dapat disimpulkan sebagai bentuk kebutuhan subunit konseling SAC.

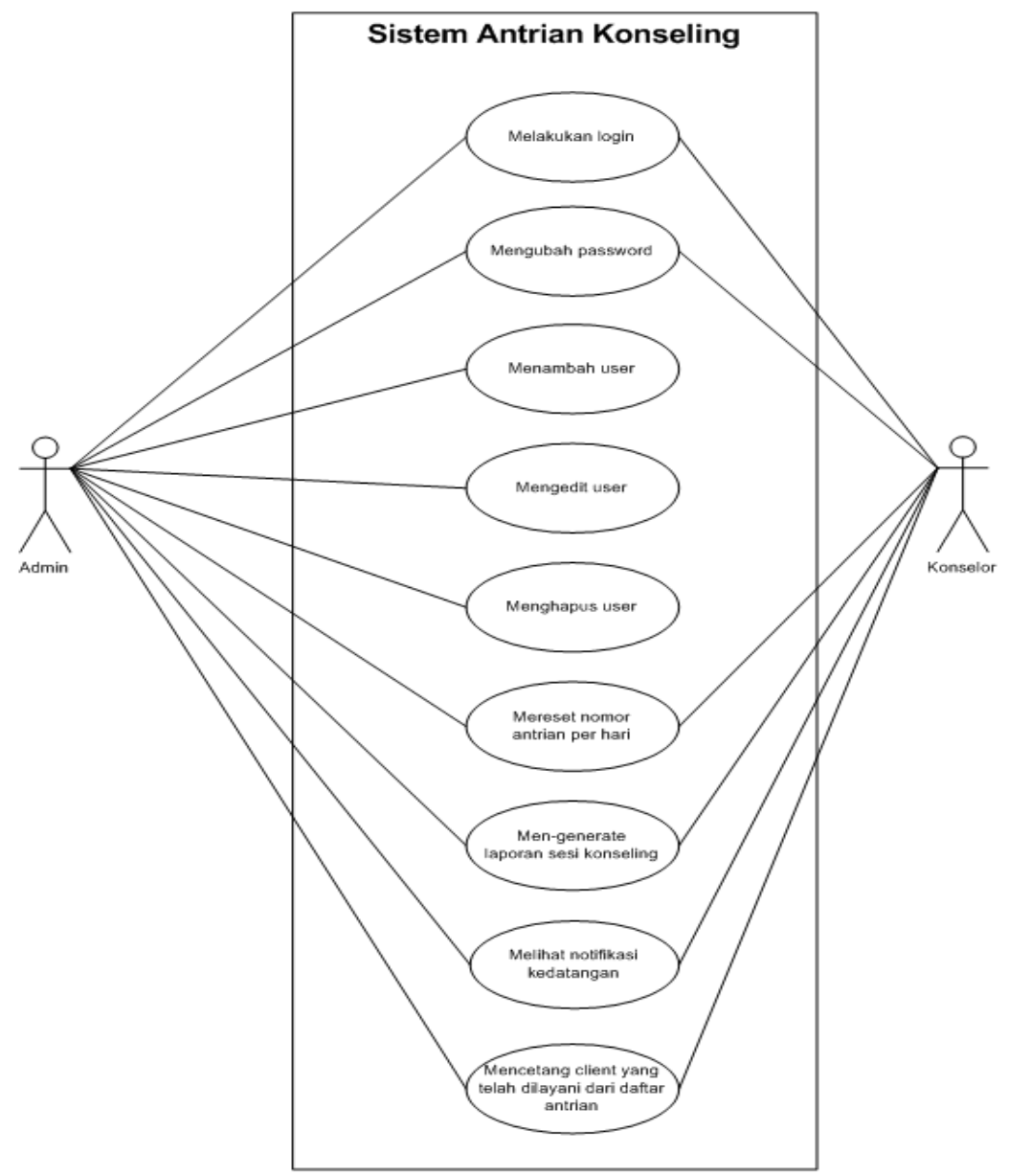

Gambar 1 Use Case Sisi Back End

Tabel 3 Use Case Specification Melakukan Login

\section{Melakukan Login}

Use Case: $\quad$ Administrator dan Konselor melakukan login ke sistem antrean konseling dengan menginput BinusianID dan password

Object: $\quad$ Administrator, Konselor, Window Login

Function: Validasi user 
Tabel 4 Use Case Specification Mengubah Password

\section{Mengubah Password}

Use Case: Administrator dan Konselor masing-masing dapat melakukan perubahan password dari account masing-masing

Object: $\quad$ Administrator, Konselor, Window User Management

Function: Update user

Tabel 5 Use Case Specification Menambah User

\begin{tabular}{ll} 
& \multicolumn{1}{c}{ Menambah User } \\
\hline Use Case: & Administrator memiliki hak untuk melakukan penambahan user \\
Object: & Administrator, Window User Management \\
Function: & Add user \\
\hline
\end{tabular}

Tabel 6 Use Case Specification Mengedit User

\section{Mengedit User}

Use Case: Administrator memiliki hak akses untuk mengedit user

Object: $\quad$ Administrator, Window User Management

Function: Update user

Tabel 7 Use Case Specification Menghapus User

\begin{tabular}{ll} 
& \multicolumn{1}{c}{ Menghapus User } \\
\hline Use Case: & Administrator memiliki hak akses untuk menghapus user \\
Object: & Administrator, Window User Management \\
Function: & Delete user
\end{tabular}

Tabel 8 Use Case Specification Mereset Nomor Antrean per Hari

\begin{tabular}{ll}
\hline & \multicolumn{1}{c}{ Mereset Nomor Antrean per Hari } \\
\hline Use Case: & $\begin{array}{l}\text { Administrator dan Konselor dapat mereset nomor antrean per harinya dari } \\
\text { angka 1 }\end{array}$ \\
Object: & $\begin{array}{l}\text { Administrator, Konselor, Window Home } \\
\text { Function: }\end{array}$ \\
\hline
\end{tabular}

Tabel 9 Use Case Specification Men-generate Laporan Sesi Konseling

\begin{tabular}{ll}
\hline & \multicolumn{1}{c}{ Men-generate Laporan Sesi Konseling } \\
\hline Use Case: & $\begin{array}{l}\text { Administrator dan Konselor dapat melakukan generate laporan sesi } \\
\text { konseling per waktu tertentu, atau per fakultas/school of atau per } \\
\text { jurusan tertentu, atau per mahasiswa tertentu }\end{array}$ \\
Object: & $\begin{array}{l}\text { Administrator, Konselor, Window Generate Report } \\
\text { Function: }\end{array}$ \\
\hline
\end{tabular}


Tabel 10 Use Case Specification Melihat Notifikasi Kedatangan

\begin{tabular}{ll}
\hline & \multicolumn{1}{c}{ Melihat Notifikasi Kedatangan } \\
\hline Use Case: & $\begin{array}{l}\text { Administrator dan Konselor dapat melihat antrean yang sedang terjadi dan } \\
\text { melihat siapa saja yang sudah dilayani dan yang belum dilayani }\end{array}$ \\
Object: & $\begin{array}{l}\text { Administrator, Konselor, Window Home } \\
\text { Function: }\end{array}$ \\
List Antrean
\end{tabular}

Tabel 11 Use Case Specification Mencetang Client yang Telah Dilayani dari Daftar Antrean

\begin{tabular}{ll} 
& Mencetang Client yang Telah Dilayani dari Daftar Antrean \\
\hline Use Case: & $\begin{array}{l}\text { Administrator dan Konselor dapat mencetang siapa saja yang sudah selesai } \\
\text { dilayani }\end{array}$ \\
Object: & Administrator, Konselor, Window Home \\
Function: & List Antrean \\
\hline
\end{tabular}

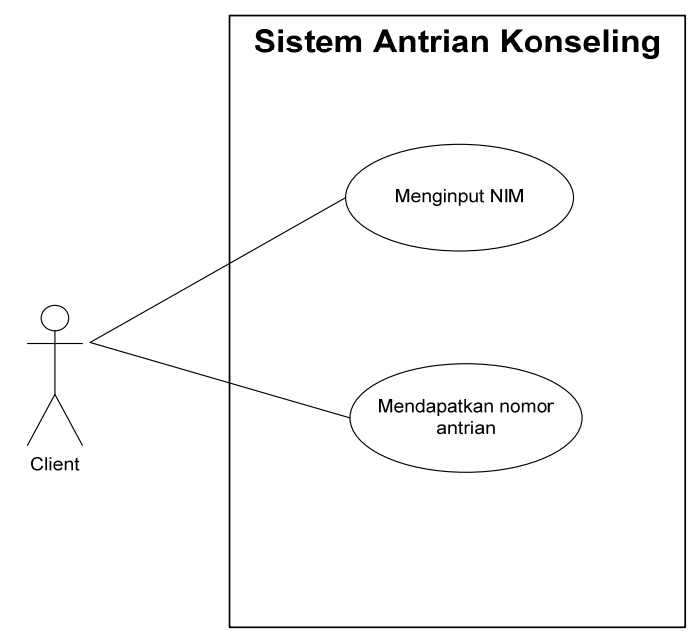

Gambar 2 Use Case Sisi Client

Tabel 12 Use Case Specification Menginput NIM

\section{Melihat Notifikasi Kedatangan}

Use Case: Client menginput NIM untuk mendapatkan nomor antrean

Object: $\quad$ Client, Window Home

Function: List Antrean

Tabel 13 Use Case Specification Mendapatkan Nomor Antrean

\begin{tabular}{ll}
\hline & \multicolumn{1}{c}{ Mendapatkan Nomor Antrean } \\
\hline Use Case: & Client mendapatkan nomor antrean setelah menginput NIM \\
Object: & Client, Window Antrean \\
Function: & List Antrean \\
\hline
\end{tabular}




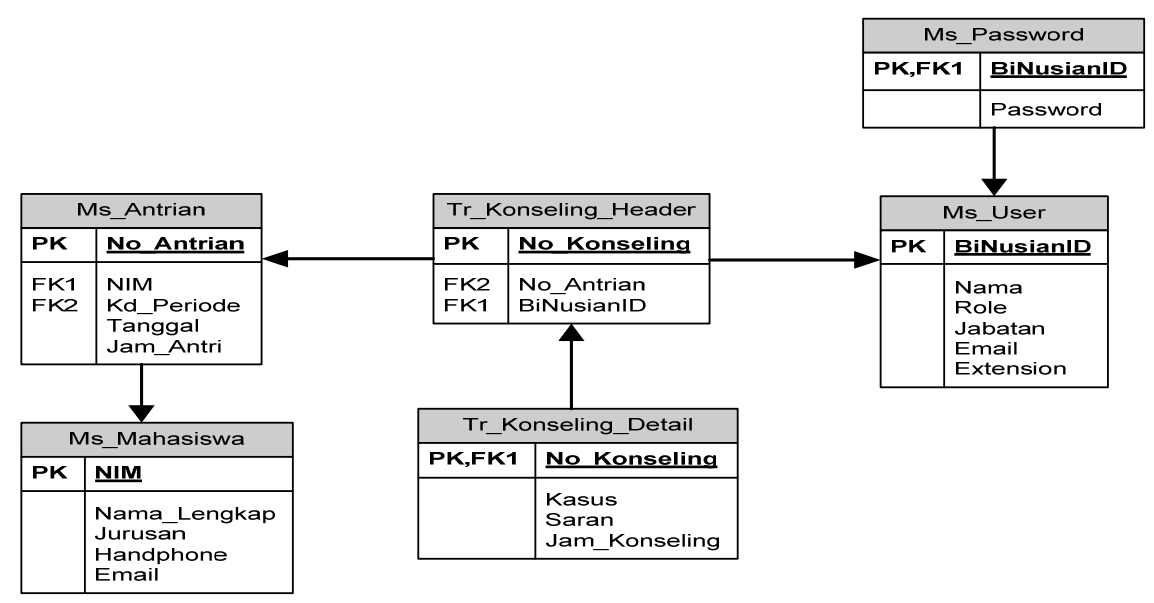

Gambar 3 ERD Sistem Antrean Konseling

\section{Decision Analysis}

Berdasarkan proses layanan konseling, kriteria sistem informasi yang didesain sebagai berikut. Pertama, mahasiswa yang membutuhkan layanan konseling mengambil nomor antrean pada aplikasi yang disediakan dengan memasukan NIM. Sistem akan memberikan nomor antrean yang nantinya akan dipanggil oleh Konselor. Kedua, para Konselor akan melihat daftar antrean dan memanggil mahasiswa mulai antrean teratas. Ketiga, selesai konsultasi, Konselor akan menginput hasil konsultasi ke sistem. Kelima, Sistem Informasi yang dibuat berbasis desktop agar kecepatan transaksi dan connection error dapat diminimalkan.

\section{Physical Design}

Tahap ini menghasilkan rancangan GUI (Graphic User Interface) Sistem Informasi antrean pada SAC. Rancangan ini dapat dilihat pada Gambar 4.

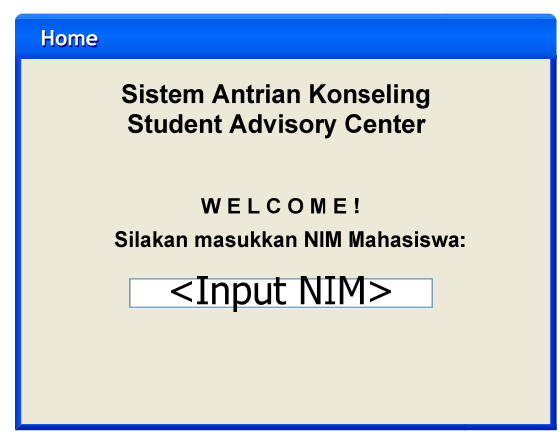

Gambar 4 Rancangan GUI User

Mahasiswa yang membutuhkan layanan konseling dapat mengambil nomor antrean pada sistem informasi antrean. Antrean diambil dengan cara menginput NIM pada kolom yang disediakan. Langkah ini terlihat pada Gambar 4. Sebagai bukti antrean, sistem akan menampilkan nomor antrean mahasiswa yang baru saja menginput NIM dengan menampilkan nomor antreannya. Hal ini tergambar pada Gambar 5. 


\section{Nomor Antrian}

Selamat Datang <Nama>

No. antrian Anda adalah:

[K01]

Gambar 5 Rancangan Layar Nomor Tiket

Konselor akan melakukan login ke aplikasi untuk dapat melayani mahasiswa (Gambar 6). Setelah melakukan login, sistem akan menampilkan antrean mahasiswa. Pada daftar antrean, terdapat keterangan apakah mahasiswa sudah dilayani atau belum. Sistem akan mencatat nama Konselor yang melayani mahasiswa. Catatan waktu mahasiswa mengambil antrean dan akhir konseling mahasiswa juga tercatat sebagai bukti mahasiswa melakukan kegiatan konseling. (Gambar 7)

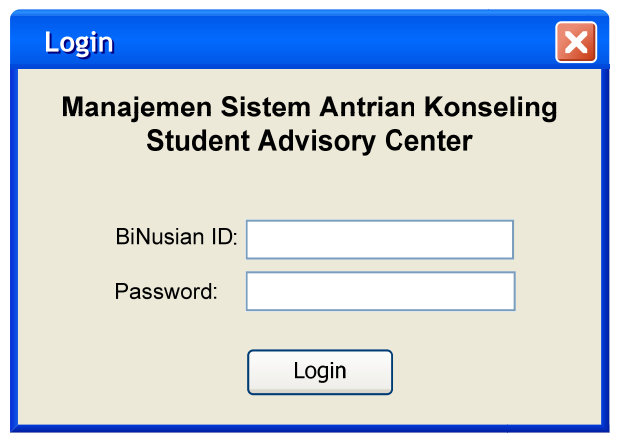

Gambar 6 Rancangan Login Konselor

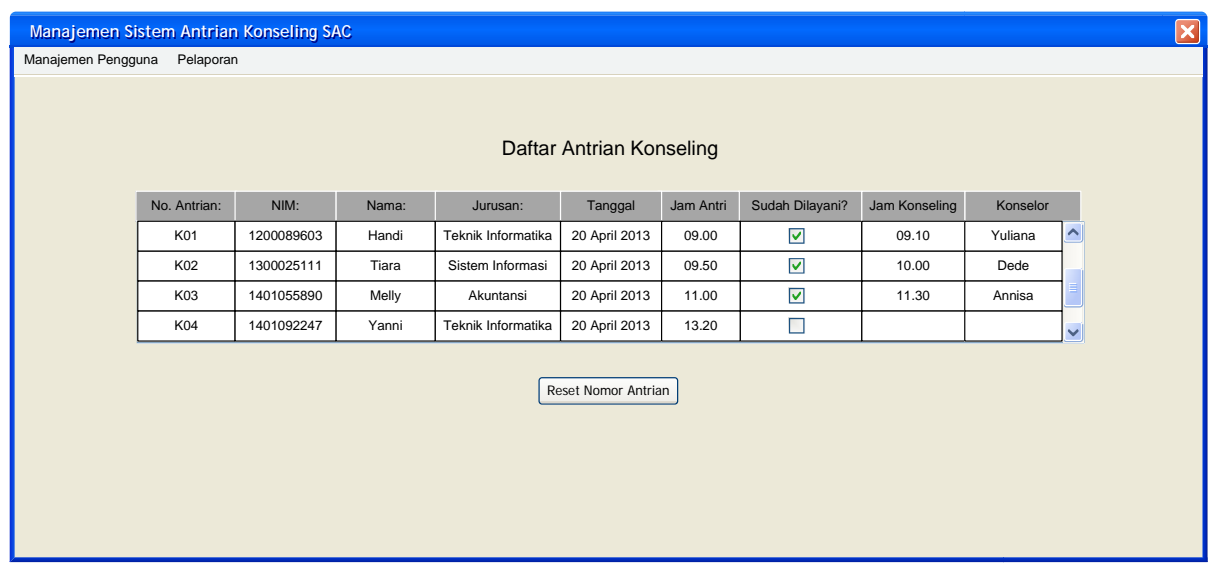

Gambar 7 Rancangan Daftar Antrean Konseling

Daftar Konselor yang dapat membuka layanan konseling dapat dilihat pada daftar pengguna. Pada menu ini Manager dapat mengatur pengguna aplikasi antrean konseling (Gambar 8). Fitur yang ditawarkan adalah tambah pengguna, jika ada Konselor baru yang ingin ditambahkan untuk membuka layanan konseling (Gambar 9). Edit pengguna, jika data Konselor yang sudah ada ingin diubah. Hapus pengguna, jika Konselor yang tidak lagi diijinkan membuka layanan konseling dan dihapus dari sistem. 


\begin{tabular}{l} 
Daftar Pengguna \\
\begin{tabular}{|c|c|c|c|c|c|c|c|}
\hline Binusian ID & Nama & Role & Jabatan & Email & Extension & Edit Pengguna & Hapus Pengguna \\
\hline 1100000111 & Yuliana & Administrator & Head Section Konseling & yuliana@binus.edu & 1234 & Edit Pengguna & Hapus Pengguna \\
\hline 1200000113 & Annisa & User & Konselor & annisa@binus.edu & 5678 & Edit Pengguna & Hapus Pengguna \\
\hline 0100000987 & Dede & User & Konselor & dede@binus.edu & 9101 & Edit Pengguna & Hapus Pengguna \\
\hline
\end{tabular} \\
\hline
\end{tabular}

Gambar 8 Rancangan Management User Konselor

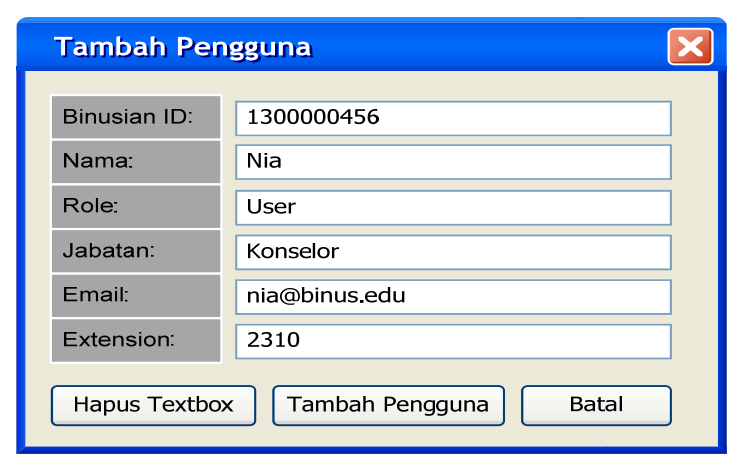

Gambar 9 Rancangan Tambah Pengguna

Hasil konseling akan dicatat oleh Konselor dalam aplikasi dengan menginput NIM mahasiswa, permasalahan yang dihadapi, dan solusi yang diberikan Konselor. Histori permasalahan yang terjadi dapat dilihat kembali oleh Konselor tersebut ataupun Konselor lainnya (Gambar 10).

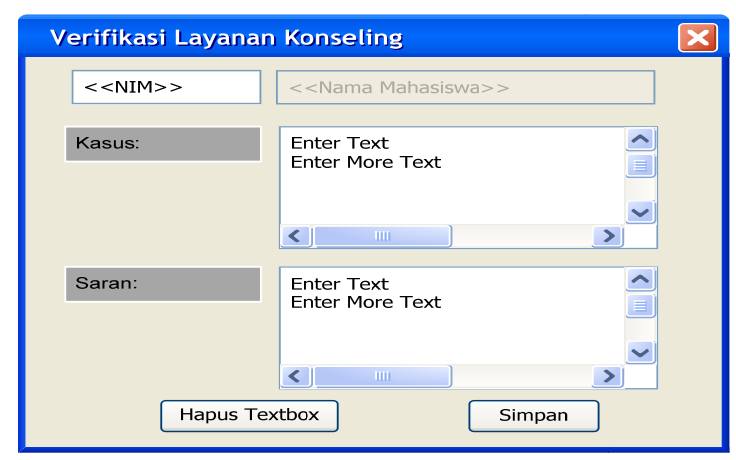

Gambar 10 Rancangan Input History Konseling

Report hasil antrean dan konsultasi dapat dilihat pada menu pelaporan. Pada menu ini Konselor diminta untuk menginput tanggal awal dan tanggal akhir history antrean yang ingin ditampilkan, Sistem akan menampilkan nomor antrean mahasiswa, NIM mahasiswa, tanggal antrean, jam datang jam mengambil antrean, nama Konselor yang melayani, sampai permasalahan mahasiswa dan saran yang diberikan oleh Konselor (Gambar 11). 


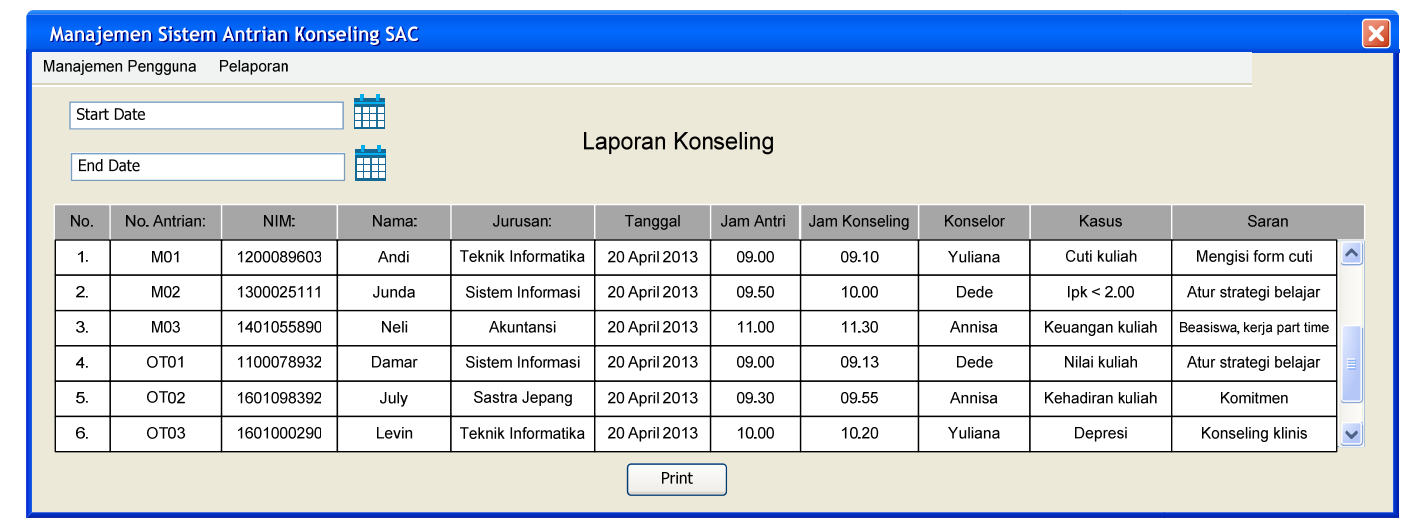

Gambar 11 Rancangan Laporan Konseling

\section{SIMPULAN}

Dengan optimasi sistem antrean, kegiatan konseling dapat berjalan lebih optimal sehingga lonjakan antrean yang terjadi pada bulan tertentu dapat ditangani dengan baik. Selain itu, history konsultasi dan kedatangan mahasiswa dapat dipantau, sehingga memudahkan Konselor dalam melihat permasalahan mahasiswa yang ditanganinya. Bagi pusat layanan yang memiliki antrean yang padat, disarankan untuk memanfaatkan sistem otomasi antrean ini sehingga dapat memberikan pelayanan yang optimal kepada para customernya. Fitur-fitur yang ada pada penelitian ini dapat disesuaikan dengan fitur yang dibutuhkan pusat layanan lainnya dengan penelitian lebih lanjut.

\section{DAFTAR PUSTAKA}

Gross, D., \& Harris, C. (1985). Fundamental of Queuing Theory. New york: Wiley.

Martha, G. N., Sukarsa, I. K., \& Kencana, I. P. (2012). Analisis sistem antrean pada loket pembayaran PT PLN (persero) area Bali selatan rayon Kuta. e-Jurnal Matematika, 1(1), 6-11.

Suryadhi, P. A., \& Manurung, N. J. (2009). Model Antrean Pada Pelayanan kesehatan di Rumah Sakit. Teknologi Elektro, 8(2), 86-93.

West, J. D., Watts, R. E., Trepal, H. C., Wester, K. L., \& Lewis, T. F. (2001). Opening space for client reflection: A postmodern consideration. The Family Journal, 9(4), 431-437. 